\title{
Simulation and Experimentation of a Single Stage Boost Inverter
}

\author{
Anand Kumar Singh, Nalin Harsh Vardhan, Deepak Verma
}

\begin{abstract}
This paper presents simulation and experimental verification of a single stage $D C$ to AC boost inverter for solar photovoltaic (SPV) applications. This topology integrates the boost converter inside the conventional h-bridge inverter topology. This eliminates the need for a separate boost converter. The whole system requires four basic switches of an h-bridge inverter for both boost and DC-AC conversion operation. Overall, the efficiency is improved because no additional switch is required for the boosting operation. The duty cycle variations are implemented using sinusoidal pulse width modulation (SPWM). The firing pulses for switches used in the h-bridge inverter are provided using Arduino-Uno platform. The principle of operation along with the simulation and experimental results are also presented.
\end{abstract}

Keywords: Solar photovoltaic systems, Single stage DC-AC boost inverter, H-bridge inverter, SPWM.

\section{INTRODUCTION}

$T_{\text {he current world is relying heavily on fossil fuel based }}$ energy sources. Not only these sources are limited in their quantity, but also they are causing global environmental issues such as global warming and climate change, thus becoming a hindrance in our effort for sustainable future. Therefore, the world is looking forward to explore various renewable sources such as solar energy and wind energy because they are inexhaustible and environment-friendly. SPV systems, which use photovoltaic (PV) cells to convert solar energy directly into electrical energy, are most commonly used for utilizing solar energy for various purposes.

There are two major concerns while extracting power from an SPV system. First, the characteristics of the load should match with those of the PV cell. Otherwise, maximum power cannot be obtained from the cell. A maximum power point tracking (MPPT) system is required for this purpose [1]. It consists of a DC-DC converter along with a closed loop

Revised Manuscript Received on October 30, 2019.

* Correspondence Author

Anand Kumar Singh*, Department of Electrical and Electronics Engineering, Birla Institute of Technology Mesra, Jaipur Campus, India. danand700@gmail.com

Nalin Harsh Vardhan, Department of Electrical and Electronics Engineering, Birla Institute of Technology Mesra, Jaipur Campus, India., nalin.vardhan173@gmail.com

Deepak Verma*, Department of Electrical and Electronics Engineering, Birla Institute of Technology Mesra, Jaipur Campus, India. deepakverma16@gmail.com

(C) The Authors. Published by Blue Eyes Intelligence Engineering and Sciences Publication (BEIESP). This is an open access article under the CC BY-NC-ND license (http://creativecommons.org/licenses/by-nc-nd/4.0/) system which continuously tracks the maximum power point (MPP) of the PV cell. There are several methods which employ different types of algorithms to carry out MPPT [2]. The other concern with PV cell is that it produces output

power at low voltage DC typically in the range of few volts. Whereas most of the general applications utilizing electrical energy work on high voltage AC typically in the order of (200-240 volts) in India and few European countries. So power conversion from low voltage $\mathrm{DC}$ to high voltage $\mathrm{AC}$ is required to be carried out in an efficient and cheap way.

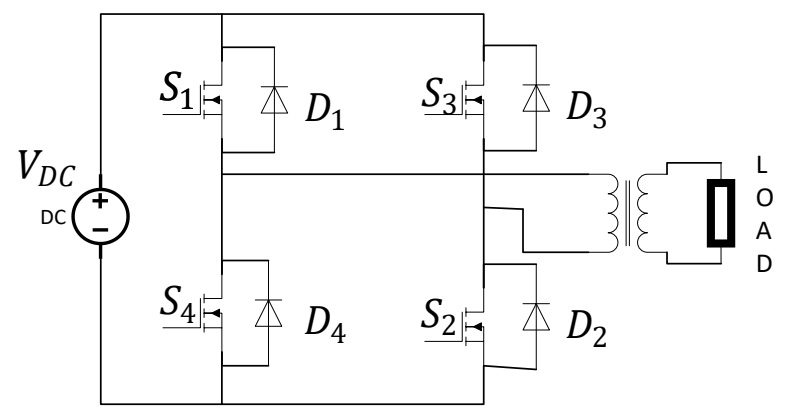

Fig.1. Conventional 2 stage DC-AC converter using transformer

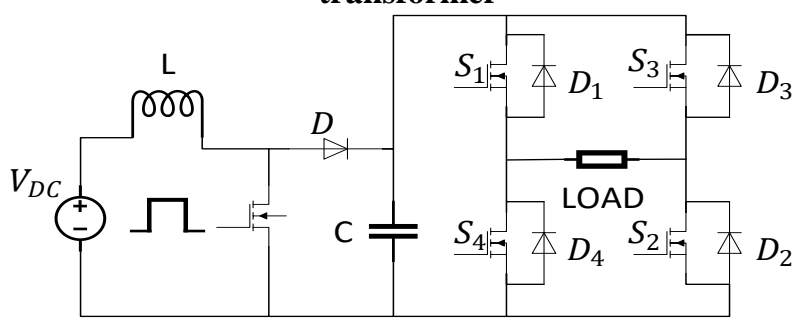

Fig.2. Conventional 2 stage DC to AC boost converter

There are in general two conventional methods used for conversion of power from low voltage DC to high voltage AC. In the first method, the low voltage DC is converted to low voltage AC using an h- bridge inverter and then boosting up the AC voltage using a step-up transformer. This system can be used for both off-grid and on-grid application Fig.1. Various SPV systems utilizing grid connected inverters are presented in [3]. The second method uses a two-stage conversion from low voltage DC to high voltage AC. In the first stage, a DC-DC boost converter is employed to boost up the low input DC voltage with high gain. If PV panel is used on the input side, then an MPPT tracking system is integrated with the boost converter. The output of the boost converter is converted to AC using an h-bridge inverter as depicted in Fig.2. A pure sinusoidal waveform is obtained at the output by employing a suitable filter.

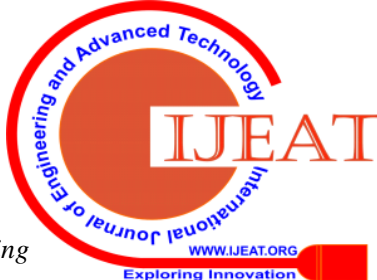


Many two stage topologies are discussed in [4]. The main problem with the first method is the use of a bulky and costly transformer. In the second method, there is an additional switch in the boost converter apart from the switches of the h-bridge inverter. This reduces the whole efficiency of the system because of increased switching losses. A separate gate drive circuit also has to be designed for the MOSFET of boost converter which adds to the total cost of the system.

There are various topologies which utilize single circuit for direct conversion of low voltage DC into high voltage AC. A boost DC-AC converter topology is presented in [5]. It has less number of components but the switching losses are high and it also suffers from electromagnetic interference problem. Kasa et al. [6] also proposed a single stage topology in which the switching losses are minimum. The main problem of this topology is that PV source cannot be utilized effectively.

This paper implements a topology proposed in [7] with the help of an Arduino Uno controller. In his paper, $\mathrm{H}$ Reberio et al. presented a topology for grid integration. Though, this paper implements this topology for standalone applications. The topology is for PV applications in which both the boost operation and the DC to AC inversion operations are done in the same circuit. The conventional h-bridge inverter is modified using two additional diodes, one inductor and a capacitor such that a boost converter is integrated inside the circuit itself (Fig.3.)

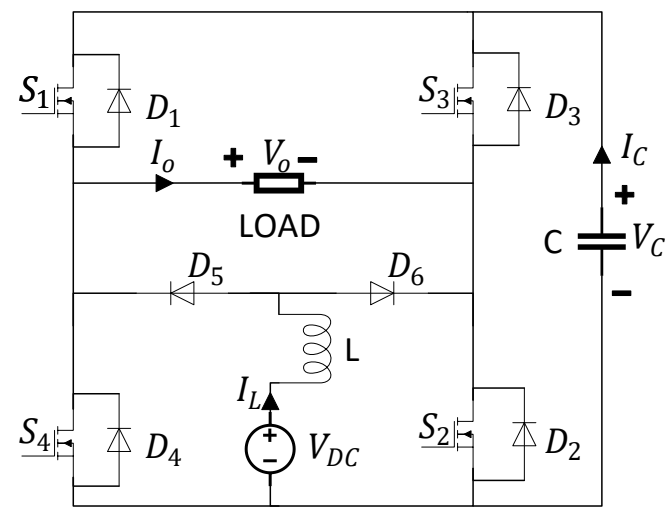

Fig.3. Single stage DC to AC boost inverter

There are basically two boost converters (which are integrated inside the h-bridge inverter) sharing the same inductor. Both of them operate consecutively in each half cycle of the output AC voltage. Sinusoidal pulse width modulation (SPWM) technique is used to provide variable duty cycle operation of switches in each half cycle. The firing pulses to the gate of switches (power MOSFET) are provided using Arduino-Uno controller. The gate drive circuit is designed by making use of suitable optocoupler ICs. The major advantages of this structure are reduced switch number, less complex circuitry, increased efficiency (because of lesser switching losses), reduction in cost, volume and weight. Next, the principle of operation of the proposed structure is presented.

\section{CIRCUIT CONFIGURATION AND WORKING}

The topology consists of four switches $\left(S_{1}, S_{2}, S_{3}\right.$ and $\left.S_{4}\right)$ with antiparallel diodes $\left(D_{1}, D_{2}, D_{3}\right.$ and $\left.D_{4}\right)$ and two power diodes $\left(D_{5}\right.$ and $D_{\epsilon}$ ). All of the switches, $S_{1}, S_{2}, S_{3}$ and $S_{4}$ are used for the inversion of boosted DC voltage appearing across the capacitor and switches $S_{4}$ and $S_{2}$ are used for the DC-DC boost operation. The antiparallel diodes are used for the charging of capacitor (both $V_{D C}$ and inductor charges the capacitor) and freewheeling of the load current. One of the diodes from $D_{\mathrm{\varepsilon}}$ and $D_{\epsilon}$ is always on. The operation can be better understood in the following subsection.

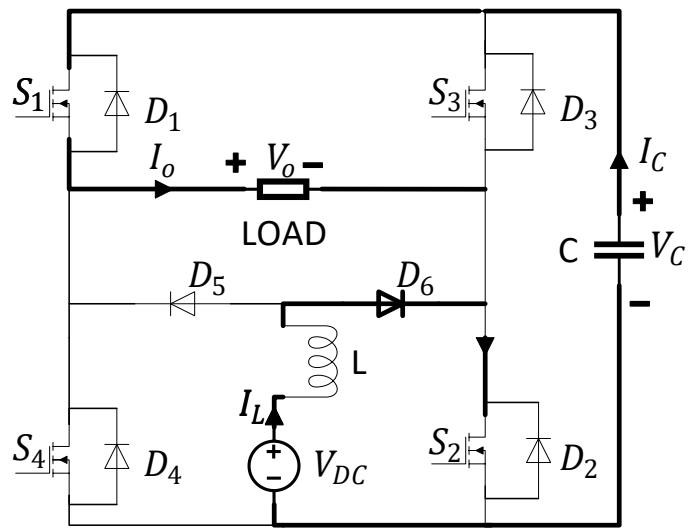

(a)

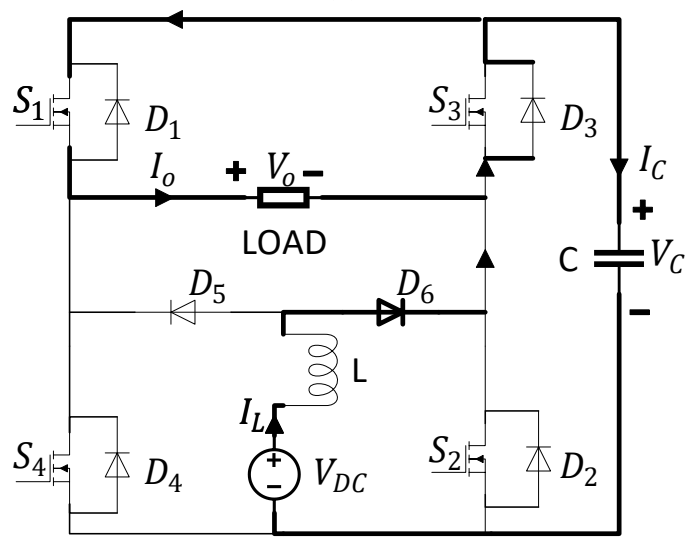

(b)

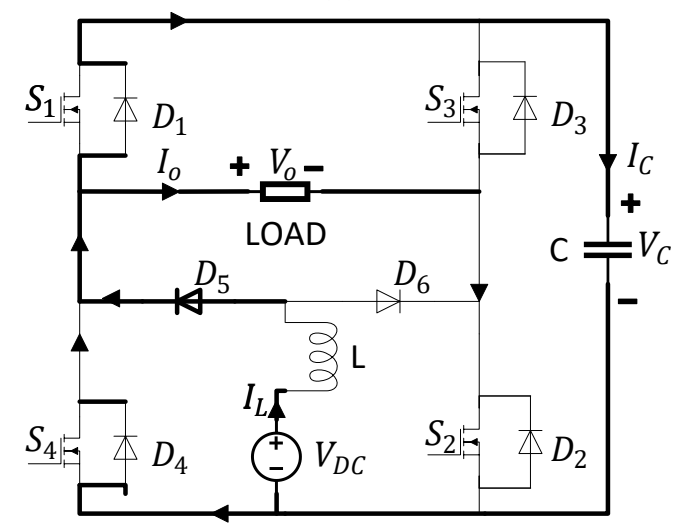

(c) 


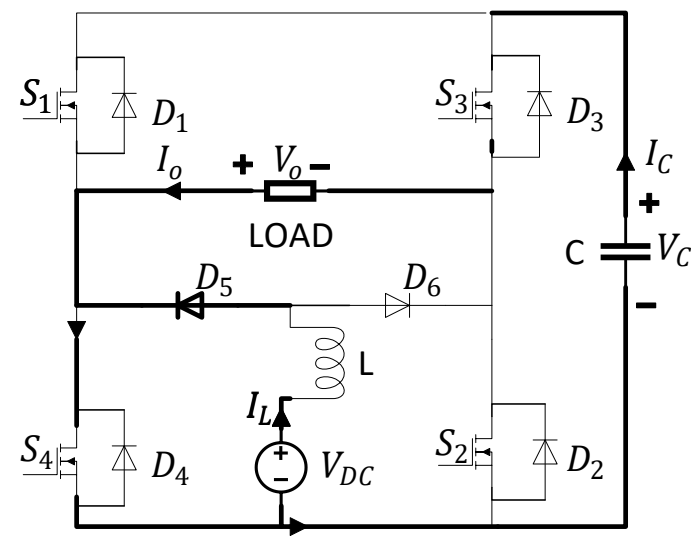

(d)

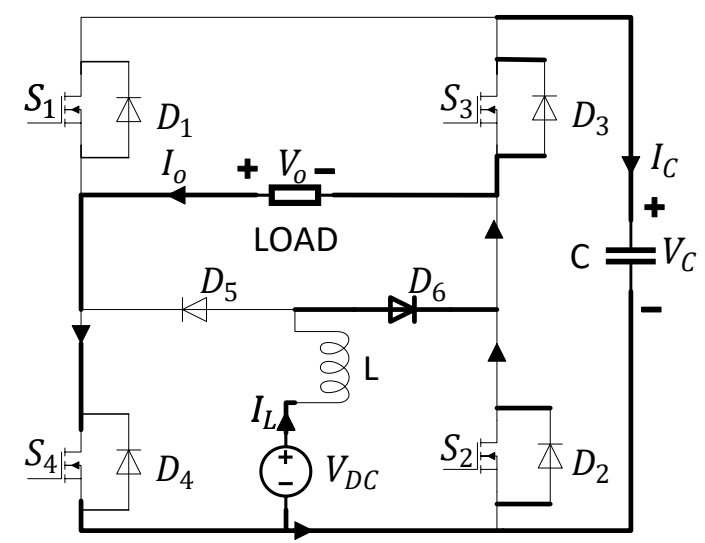

(e)

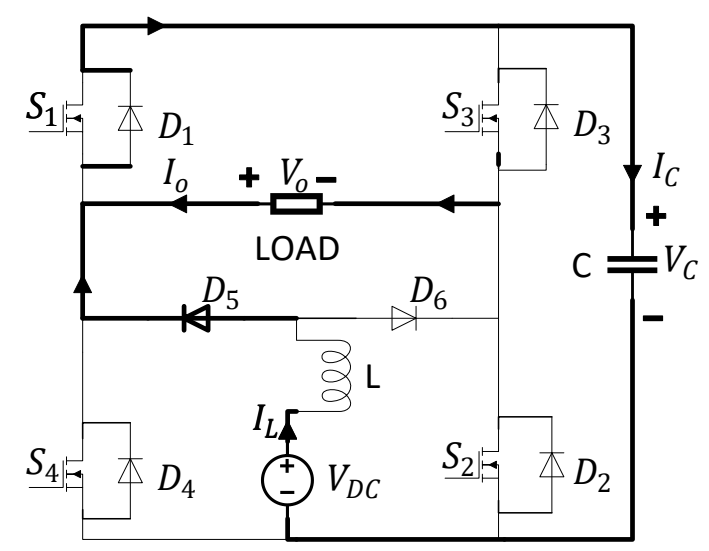

(f)

Fig.4. Various modes of operation of the single stage DC-AC boost inverter. (a.) Mode 1(b.) Mode 2 (c.) Mode 3(d.) Mode

\subsection{Operation:}

4 (e.) Mode 5 (f.) Mode 6.

During mode 1 switches $S_{1}$ and $S_{2}$ are on, and switches $S_{3}$ and $S_{4}$ are off. Capacitor discharges through $S_{1}$, load and $S_{2}$. Current through the inductor rises through voltage source $\left(V_{D C}\right), D_{\epsilon}$ and $S_{2}$. Thus, in this mode the inductor stores energy. Meanwhile the capacitor loses its stored energy and supplies power to the load. During mode 2 switch $S_{2}$ is off while switch $S_{1}$ is on. Load current freewheels through $S_{1}$

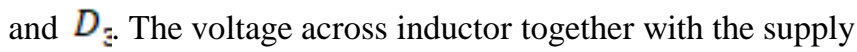
voltage is applied across the capacitor. Thus the capacitor starts charging through $D_{\epsilon}$ and $D_{\xi}$. This is actually where the boost operation is performed. Since the charging path of the capacitor has less resistance compared to the discharging path, overall a boost of voltage across the capacitor is observed. The operation of mode 3 is similar to that of mode 2. The only difference is that the capacitor charges through diodes $D_{1}$ and $D_{\varepsilon}$ and the load current freewheels through switch $S_{2}$ and diode $D_{4}$. The operation of mode 4 is similar to that of mode 1 . The capacitor discharges through $S_{5}$, load and $S_{4}$. Inductor current flows through voltage source $\left(V_{D C}\right)$, $D_{\varepsilon}$ and $S_{4}$. The operation of modes 5 and 6 are similar to that of modes 2 and 3.

The switching frequency of the boost converter which is integrated inside the circuit is equal to the switching frequency of carrier wave used for SPWM implementation. Because of this the duty cycles given to switches $S_{4}$ and $S_{2}$ vary sinusoidally. Due to variable duty cycle, the boost converter never attains the steady state. In other words, the energy storage elements (the inductor and the capacitor) always remain in transient state. Generally, a DC - DC converter is said to be in the steady state if net energy of the energy storage elements remains constant after each switching cycle i.e. the average current and the average voltage across the inductor and capacitor remain constant; but because of continuous switching, they contain ripples. But in this case the average inductor current and the average capacitor voltage does not remain constant after each switching cycle (time period of the carrier wave used in SPWM) because of the sinusoidally varying duty cycle. They also vary sinusoidally. Hence the conventional steady-state equations developed for DC-DC boost converter cannot be applied in this case for the calculation of inductance and capacitance. Apart from sinusoidal variations in their average values, the inductor current and capacitor voltage also contain ripples.

\subsection{Calculations:}

If carrier frequency is too high, then continuous conduction can be assumed [8].

Let the max and min duty cycle be $D_{\max }$ and $D_{\min }$ respectively.

Let $\mathrm{t}=0$ be the start time of any arbitrary switching cycle

Let $f_{s}$ be the frequency

Therefore, one switching cycle will be:

$$
\mathrm{T}=\frac{1}{f}
$$

Let $\mathrm{D}$ be the duty ratio of one switching cycle.

Let $T_{O N}$ be the duration of mode 1

Hence $T_{\text {ON }}=D \times T$

1.) For mode-(1.) $\quad\left(0<t<T_{\text {on }}\right)$

$V_{L}=V_{D C}=L \frac{d T_{L}}{d t}$

Or, $\int_{0}^{T_{O D N}} V_{D C} d t=L \int_{I_{L \min }}^{I_{L \max }} d I_{L}$

(Where $I_{L \min }$ and $I_{L \max }$ are minimum and maximum values of $I_{L}$ in the switching cycle.)

$V_{D C} T_{O N}=L\left(\Delta I_{L}\right) . \quad\left(\Delta I_{L}=I_{L \max }-I_{L \min }\right)$.

Using eq-(1.) and eq-(2.)

$$
L=\frac{V_{D C} D}{\Delta_{L f} f}
$$

Where $D_{\min }<D<D_{\max }$

Accordingly, range of values of $L$ can be calculated.

$I_{C}=C \frac{d V_{C}}{d t}$

For $0<t<T_{\text {ON }}$

$I_{C}=I_{0}$ 
$\int_{0}^{T_{O N}} I_{0} d t=\int_{V_{\text {Conin }}}^{V_{\text {Cumx }}} d V_{C}$

(Where $V_{\text {Cmin }}$ and $V_{\text {Cmax }}$ are minimum and maximum voltage across capacitor in the switching cycle).

$$
\begin{gathered}
I_{O} T_{O N}=C \Delta V_{C} \quad\left(\Delta V_{C}=V_{C \max }-V_{C \min }\right) \\
I_{O} D T=C \Delta V_{C} \\
C=\frac{I_{D} D}{\Delta V_{C f}}
\end{gathered}
$$

Where $D_{\min }<D<D_{\max }$

Thus, range of values of $\mathrm{C}$ can be determined

2.) For mode 2 or mode 3 ,

$T_{\text {ON }}<t<T$

Applying KVL

$V_{D C}-V_{L}-V_{C}-V_{C m i n}=0$

$V_{D C}-V_{C \min }=V_{L}+V_{C}$

$V_{C \max }-V_{C \min }=L \frac{d t_{L}}{d t}+\frac{1}{C} \int I_{L} d t$

Taking Laplace transform,

$\frac{V_{D C}-V_{\text {Gmin }}}{s}=L S I_{L}(s)-I_{L \text { min }}+\frac{I_{L}(s)}{\sigma s}$

$I_{L \min }+\frac{V_{D E}-V_{C \min }}{s}=\frac{\left(L C S^{2}+1\right)}{\sigma} I(s)$

$\frac{I_{L \min } C S}{L C S^{2}+1}+\frac{\left(V_{D E}-V_{G \min }\right) C S}{L C S^{2}+1}=I_{L}(s)$

Solving and taking inverse Laplace transform

$\frac{I_{L \min }}{L} \cos \frac{t}{\sqrt{L C}}+\left(V_{D C}-V_{C \min }\right) \sqrt{\frac{C}{L}} \sin \frac{t}{\sqrt{L C}}=I_{L}$

Now,

$V_{C}=\frac{I}{C} \int_{T_{O N}}^{T} I_{L}(t) d t$

$=\frac{1}{C} \int_{T_{D N}}^{T}\left(\frac{u_{L \min }}{L} \cos \frac{t}{\sqrt{L C}}+\sqrt{\frac{C}{L}} \sin \frac{t}{\sqrt{L C}}\right) d t$

$V_{C}=\frac{t_{L \min }}{\sqrt{U C}}\left[\sin \frac{t}{\sqrt{L C}}-\sin \frac{D T}{\sqrt{L C}}\right]+\left(V_{D C}-V_{C \min }\right)\left[\cos \frac{D T}{\sqrt{L C}}-\right.$ $\left.\cos \frac{t}{\sqrt{L C}}\right]$

Putting value $\mathrm{t}=\mathrm{T}$ and $D_{\min }<D<D_{\max }$, value $V_{C}$ at the end of the mode-(2.) and mode-(3.) can be obtained.

The calculations for mode 4 are similar to those of mode 1 and the calculations for mode 5 and mode 6 are similar to those of mode 2 and mode 3 .

\section{IMPLEMENTATION USING MATLAB SIMULINK}

The presented structure was modeled in MATLAB simulink and the results were analyzed as follows. An ideal DC supply of $12 \mathrm{~V}$ was taken to verify results. A $550 \Omega$ resistance block was used as load for testing purpose. The parameters used for the simulation are given in the Table 1 . A suitable LC filter was connected across the load resistance to obtain pure sinusoidal voltage and current waveforms.

Table 1: Simulation Parameters

\begin{tabular}{lc}
\hline \multicolumn{1}{c}{ Components } & Values \\
\hline Inductor $(L)$ & $10 \mathrm{mH}$ \\
Capacitor $(C)$ & $500 \mu \mathrm{F}$ \\
Load resistance & $550 \Omega$ \\
Filter Inductance $\left(L_{f}\right)$ & $5 \mathrm{mH}$ \\
Filter Capacitance $\left(C_{f}\right)$ & $500 \mu \mathrm{F}$ \\
\hline
\end{tabular}

3.1 SPWM Implementation:

The technique used for producing variable duty cycle to the switches of the h-bridge is SPWM. In both simulation and hardware testing, unipolar switching technique is used (Fig. 5).Two modulating signals were used as reference. Each one of them is sine wave ( $180^{\circ}$ out of phase) with frequency $50 \mathrm{~Hz}$. A triangular wave with frequency of $500 \mathrm{~Hz}$ is used as carrier wave. The modulation index was kept at 0.8 . The control logic is given as:

When mod (1) $>\mathrm{A}_{\mathrm{C}}, S_{1}$ is on, $S_{4}$ is off; When mod (1) $<\mathrm{A}_{\mathrm{C}}$, $S_{4}$ is on, $S_{1}$ is off; When $\bmod (2)>\mathrm{A}_{\mathrm{C}}, S_{\mathrm{g}}$ is on, $S_{2}$ is off; When $\bmod (2)<\mathrm{A}_{\mathrm{C}}, S_{2}$ is on, $S_{\mathrm{g}}$ is off.

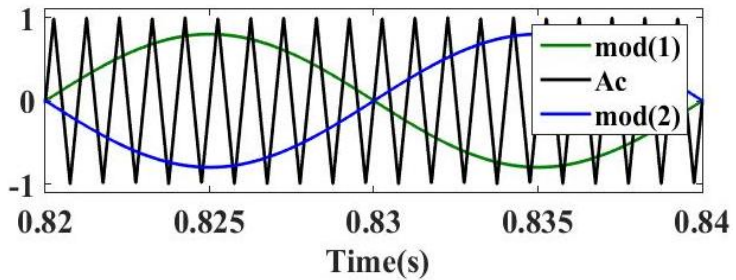

(a)

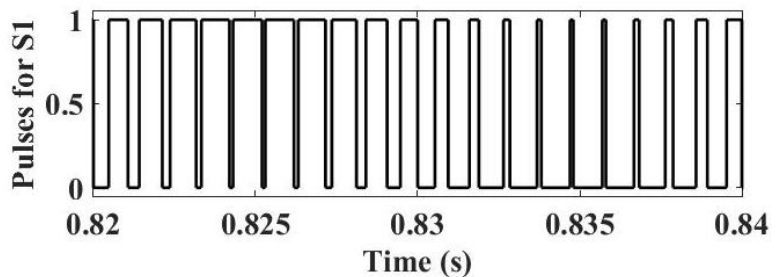

(b)

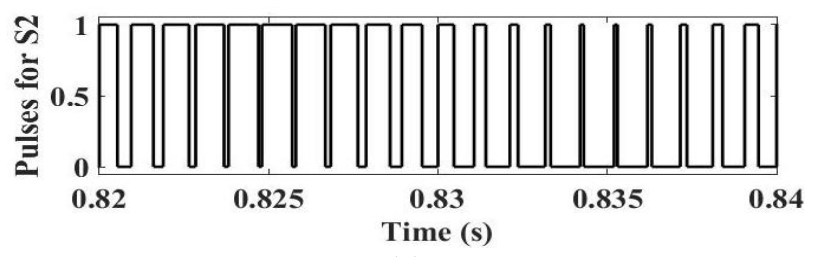

(c)

(d)
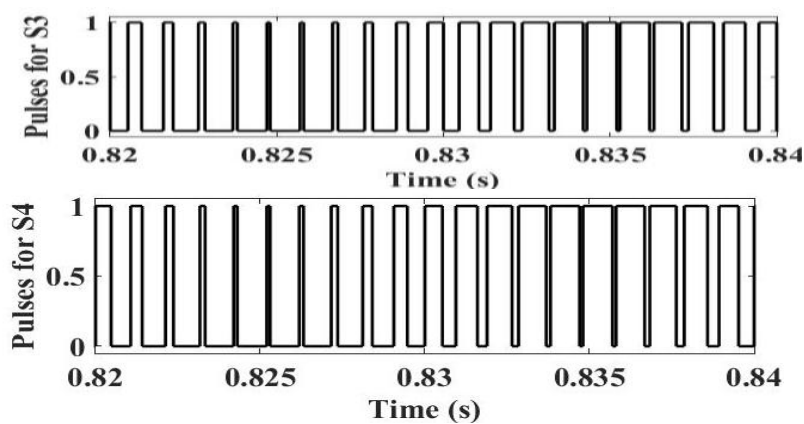

(e)

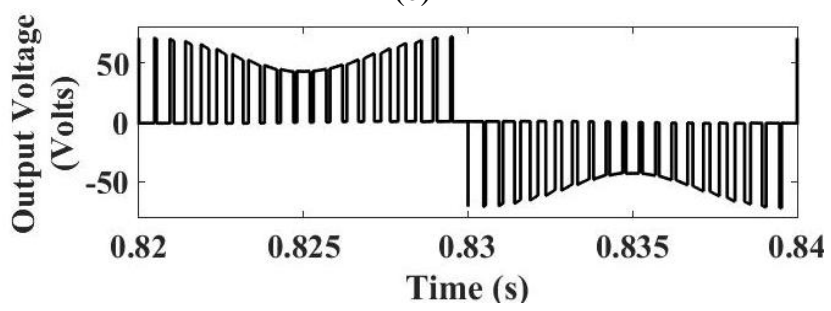

(f) 


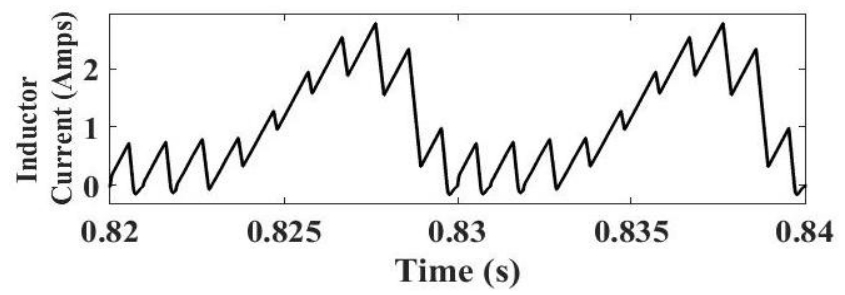

(g)

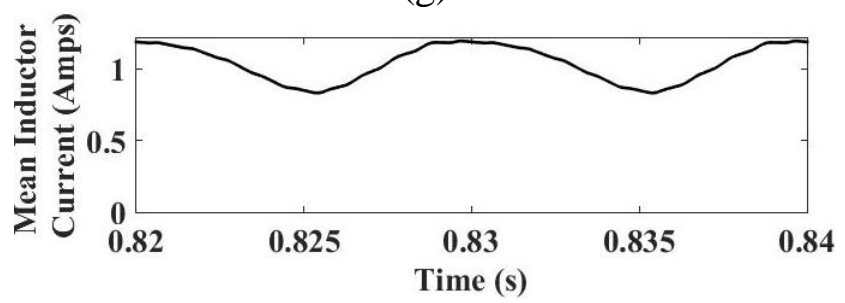

(h)

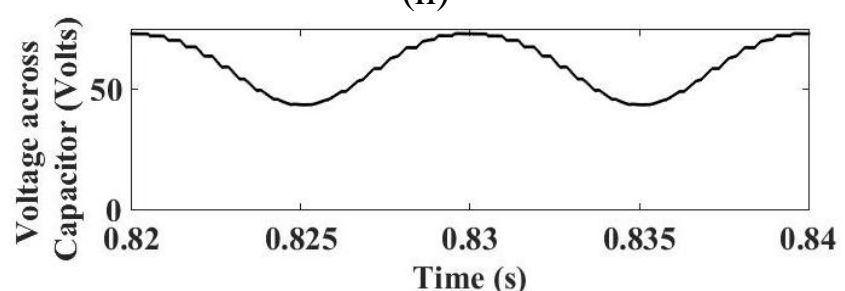

(i)

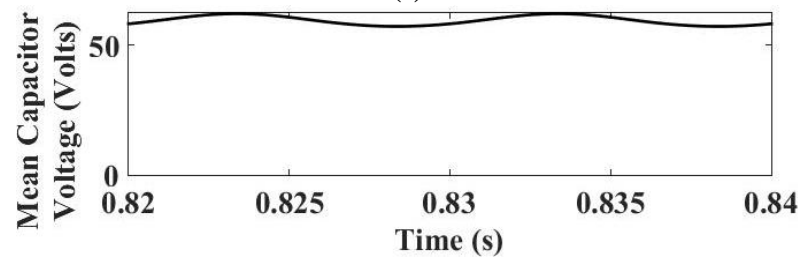

(j)

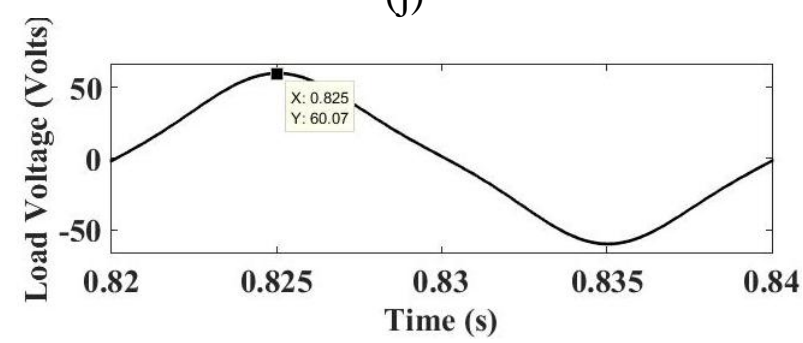

(j)

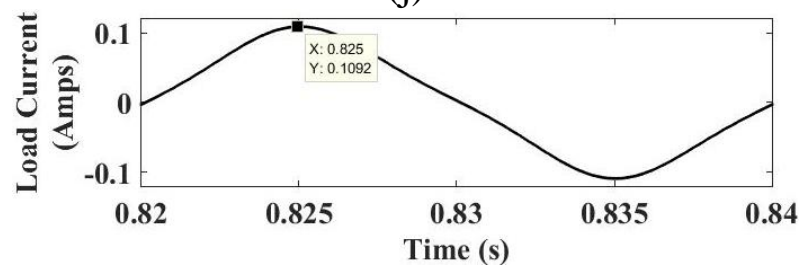

(k)

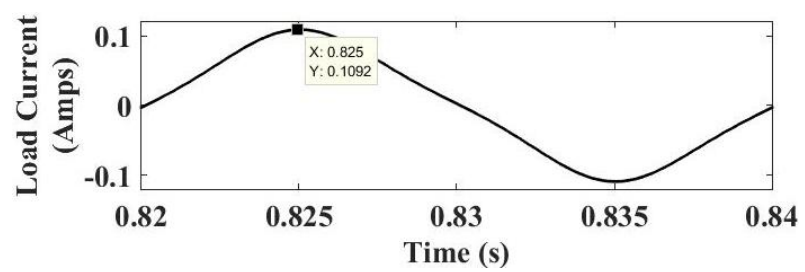

(l)

Fig.5. Simulation results (a.) SPWM, (b.) Gate pulse for $S_{1}$, (c.) Gate pulse for $S_{2}$, (d.) Gate pulse for $S_{3}$, (e.) Gate pulse for $S_{4}$, (f.) Output voltage, (g.) Inductor current, (h.) Mean inductor current, (i) Capacitor voltage, (j.) Mean capacitor voltage, (k.) Load voltage and (l.) Load current.
From the simulation results, it is observed that for input DC voltage of $12 \mathrm{~V}$, AC output voltage of $60.07 \mathrm{~V}$ (peak) is obtained. A pure sinusoidal waveform is obtained across the load because of filter capacitor and inductor. It can be seen from the result that the average values of inductor current and capacitor voltage are not constant instead, they vary sinusoidally. Hence, the energy storage elements always remain in transient condition. The input current drawn from the DC source can be further reduced using high switching frequency. This can be done by increasing the frequency of the carrier signal used in SPWM implementation. By this way efficiency of system can be further improved.

\section{EXPERIMENTAL VERIFICATION}

The design parameters for different component used are given in the Table 2.

Table 2. Design Parameters

\begin{tabular}{ll}
\hline Switch & Power MOSFET(IRFP250NPbF) \\
Power diode & 16FM120 \\
Optocoupler & TLP 250H \\
Inductor & Torroidal Ferrite Core Based $(2.28 \mathrm{mH})$ \\
Capacitor & $400 \mathrm{~V}, 680 \mu \mathrm{F}$ \\
\hline
\end{tabular}

\subsection{Design of Inductor:}

A toroid shaped ferrite core based inductor was designed. Inductance of each inductor was kept $2.28 \mathrm{mH}$. Four such inductors were connected in series to obtain a desired inductance near to $9.12 \mathrm{mH}$.

The formula for inductance of toroid shaped inductor is given as:

$$
L=\frac{\mu_{o} \mu_{r} N^{2} A}{2 \pi r}
$$

Where $\mu_{\epsilon}=4 \pi \times 10^{-7} \mathrm{H} / \mathrm{m}$ (permeability of free space)

$\mu_{r}=1000$ (relative permeability of ferrite core)

$\mathrm{N}=$ number of turns

$\mathrm{A}=$ area of cross sections

$\mathrm{R}=$ mean radius of toroid

Keeping $\mathrm{N}=36, \mathrm{~A}=1.32 \mathrm{~cm}^{2}$ and $\mathrm{r}=1.4 \mathrm{~cm}$, the value of inductance obtained from above equation is $2.28 \mathrm{mH}$.

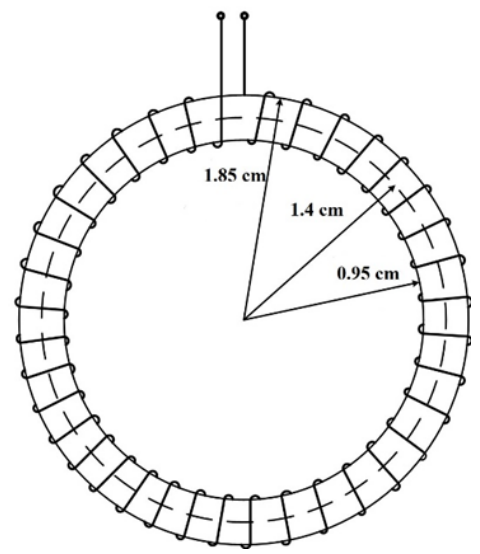

Fig.6. Dimensions of ferrite core

\subsection{Experimental Setup:}

Published By:

Blue Eyes Intelligence Engineering 


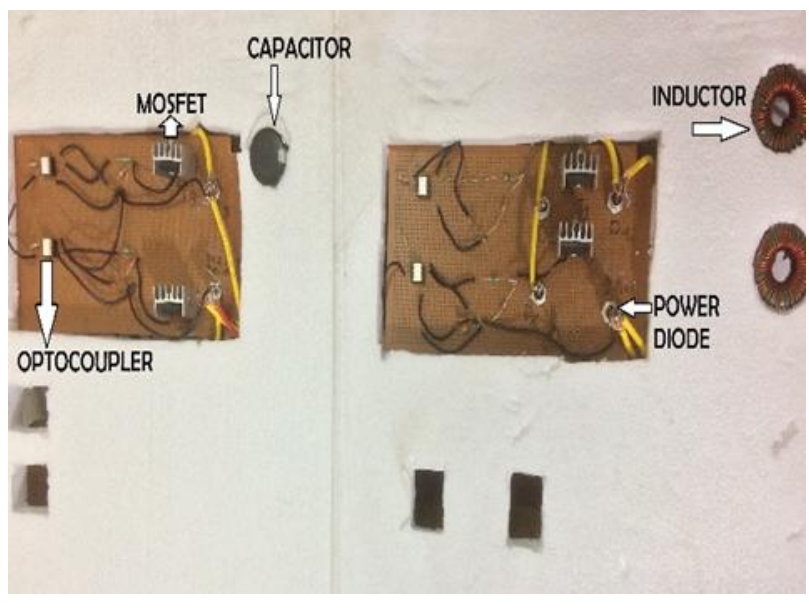

(a)

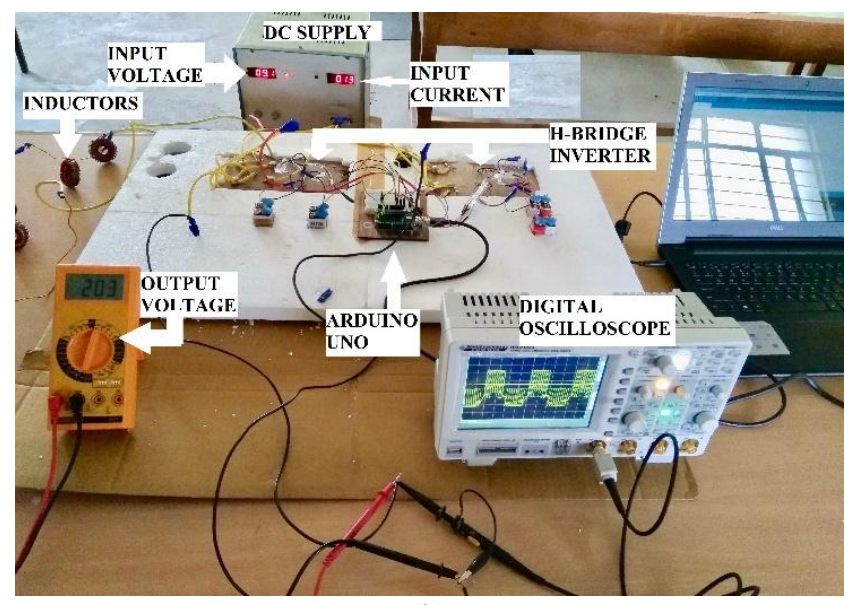

(b)

Fig.7 Fabrication and implementation of the presented structure (a) Prototype model and b) Experimental setup 4.3 Testing and Results:

\subsubsection{No Load Testing:}

The input DC supply taken in use was 'Regulated DC Power Supply'. The firing pulses were given to the power MOSFET switches Arduino Uno Board. The SPWM logic was implemented by writing a program on open source Arduino Software (IDE). Optocoupler IC TLP 250 was used for designing the gate drive circuit of the MOSFET. The Gate Drive Circuit was mainly used for serving the purpose of isolation and amplification.

First, the performance of the h-bridge inverter was checked. Before connecting it to diodes $D_{\mathrm{s}}, D_{\epsilon}$, inductor and capacitor. To test the performance of the inverter, the switches $S_{1}$ and $S_{2}$ were given firing pulses for the first half cycle and the switches $S_{3}$ and $S_{4}$ were given firing pulses for the next half cycle. The switching frequency was kept $1 \mathrm{khz}$. Fig.8. (a.) shows the firing pulses obtained on digital oscilloscope. The input side of the inverter was connected to DC supply and an input voltage of $24 \mathrm{~V}$ was given. Fig.8.(b.) shows the obtained results. An exact output frequency of $50 \mathrm{~Hz}$ was successfully obtained and there was very low DC component in the output.

After successful testing of the h-bridge inverter, the actual proposed topology was fabricated and tested. For an input voltage 9.1V DC, a boosted voltage of 203V (rms) AC was obtained. The results are shown in Fig.7. (b.). The output voltage waveform (after attenuating by a factor of 10) is shown in Fig.8. (c.). When the input supply was disconnected, there was still voltage across the load terminals because of the charged capacitor Fig.8. (d.).

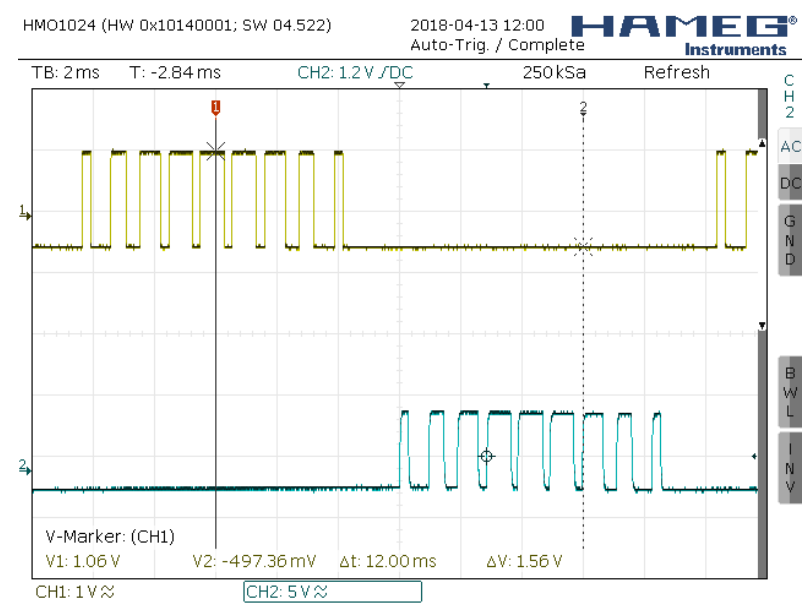

(a)

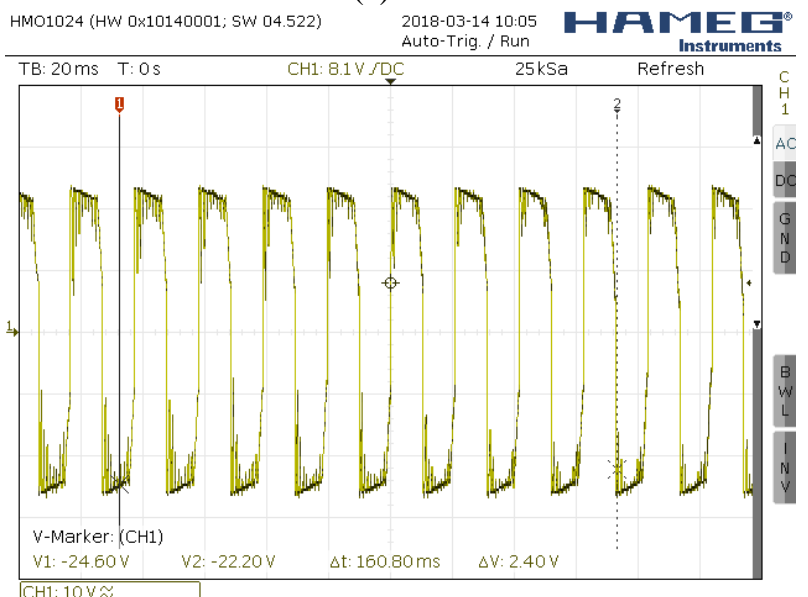

(b)

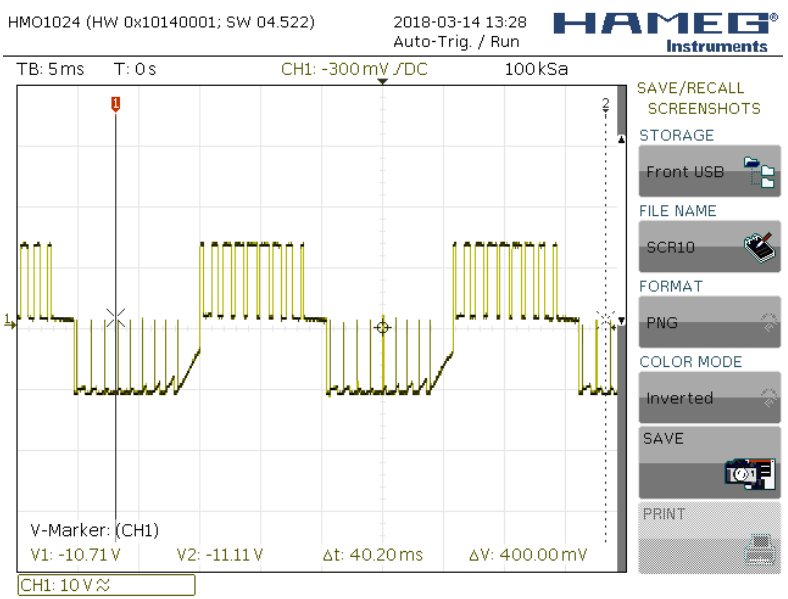

(c) 


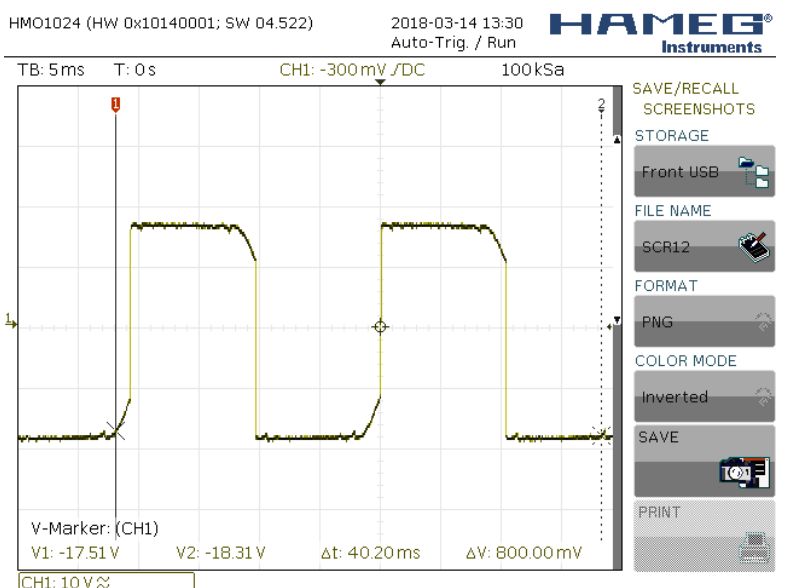

(d)

Fig.8. Experimental results (a.) Switching pulses, (b.) Output voltage waveform of h-bridge inverter circuit, (c.) Output voltage waveform of DC-AC boost inverter and (d.) Output voltage across load terminals when input supply is disconnected.

\subsubsection{Testing with PV Panel :}

Two solar panels (open circuit voltage rating of $21 \mathrm{~V}$ and short circuit current rating of 5.98A) of $100 \mathrm{~W}$ were connected in parallel. The input current and input voltage obtained from the panel were 1.8A and 15.3V respectively. A rheostat of 298 $\Omega$ was used for varying the load. An AC output voltage of $35.2 \mathrm{~V}$ (rms) was obtained. The capacitor was charged up to 51V. The results are shown in Fig.9.(a.). The circuit was also tested with a load (incandescent lamp of 100W) Fig.9.(b.). The load testing was done with input DC voltage of $9.1 \mathrm{~V}$ obtained from regulated DC supply.

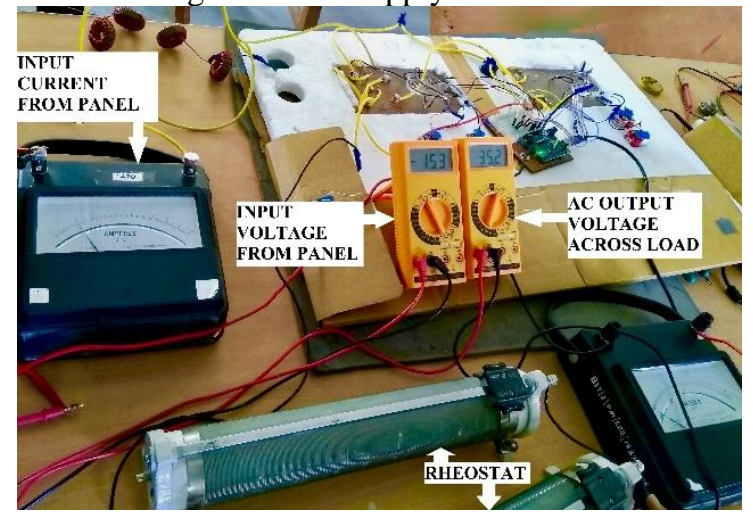

(a)

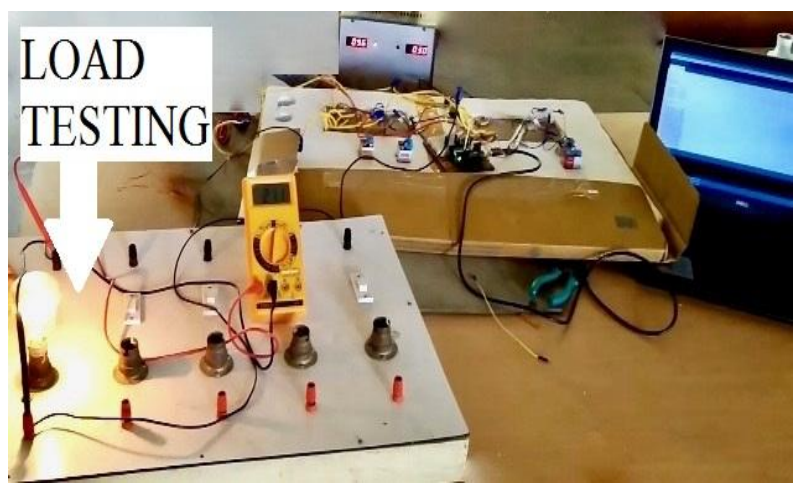

(b)

Fig.9. (a.) Testing with PV panel, (b.) Load testing with 100W bulb.

\section{CONCLUSION}

In this paper, results which were obtained from the hardware prototype testing of a single stage DC to AC boost inverter are presented along with various simulation results. From experimental analysis it can be concluded that this topology has some major advantages over conventional two stage topologies such as lesser switch number, increased efficiency as well as reduction in overall cost, weight and volume of the system. It is also shown that by integrating the boost converter in the h- bridge inverter topology itself, and varying the duty cycle by implementing SPWM, boost operation is done twice in a complete cycle of AC output voltage. By using appropriate passive filter on the load side, the converter can be used effectively for transferring the power from PV systems to standalone electrical utilities.

\section{FUTURE SCOPE}

Since a boost converter is integrated inside the topology itself, the circuit can also be used for MPPT. The conventional MPPT systems utilize direct duty cycle variations to track maximum power point. But in this case direct duty cycle variations are not possible because of implementation of SPWM. The closed loop MPPT system should be designed such that it varies the modulation index to track maximum power point. Another possible future scope for this topology is grid synchronization. This topology can be converted into a single stage grid synchronized AC module for SPV systems.

\section{REFERENCES}

1. John H. R. Enslin, Mario S. Wolf, Daniel B. Snyman, and Wernher Swiegers, "Integrated Photovoltaic Maximum Power Point Tracking Converter" in IEEE Transactions on Industrial Electronics, Vol. 44, no. 6, December 1997.

2. Bidyadhar Subudhi and Raseswari Pradhan, "A Comparative Study on Maximum Power Point Tracking Techniques for Photovoltaic Power Systems," IEEE Transactions on Sustainable Energy, Vol. 4, No. 1, January 2013.

3. Soeren B. Kjaer, John K. Pedersen and Frede Blaabjerg, "A Review of Single-Phase Grid Connected Inverters for Photovoltaic Modules", in IEEE Transactions on Industry Applications, Vol. 41, No. 5, 2005.

4. Meneses, D. and Blaabjerg, F. and Gracia, O. and Cobbs, J.A.: "Review and Comparison of Step-Up Transformer less Topologies for Photovoltaic AC- Module Application.” IEEE Power Electron, 2013, 28, (6), pp. 2649-2663

5. Caceres, R.O. and Barbi, I,: "A boost DC-AC Converter: Analysis, Design, and Experimentation.” IEEE Power Electron, 1999, 14, (1), pp. 134-141.

6. Kasa, N. and Lida, T. and Iwamoto H.: "Maximum Power Point Tracking with Capacitor Identifier for Photovoltaic Power System.” in Proc. IEEE Electric Power Applications conf, November 2000, pp. 497-502.

7. H. Riberio, A. Pinto, and B. Borges, "Single Stage DC-AC Converter for Photovoltaic Systems" in Energy Conversion Congress and Exposition (ECCE), 2010 IEEE, pp. 604-610, 2010.

8. Verma, D., Nema, S. and Shandilya, A.M., "A different approach to design nonisolated DC-DC converters for maximum power point tracking (MPPT) in solar photovoltaic systems". Journal of Circuits, Systems, and Computers: World Scientific Publication, 25(8), 2016, pp. 1630004 


\section{AUTHORS PROFILE}

Anand Kumar Singh has done his Bachelor of Engineering in Electrical and Electronics from Birla Institute of Technology, Mesra, India in 2018. His research work includes solar inverter, maximum power point tracking controller and single stage DC-AC boost inverter.

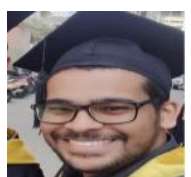

Nalin Harsh Vardhan has done his Bachelor of Engineering in Electrical and Electronics from Birla Institute of Technology, Mesra, India in 2018. His research work includes power electronics, maximum boost inverter. power point tracking controller and single stage DC-AC

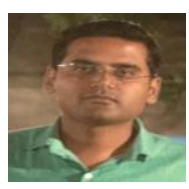

Deepak Verma received BE degree in Electrical \& Electronics Engineering from RGTU, Bhopal in 2008. He has completed his M. Tech. and Ph.D. from Maulana Azad National Institute of Technology Bhopal in 2010 and 2016. He is currently working as an Assistant Professor in the Department of Electrical \& Electronics Engineering, Birla Institute of Technology Mesra, Jaipur Campus, India. His research interest includes performance optimization of solar PV array and maximum power point tracking in solar PV systems. His publications include 8 h-indexed (Thomson Reuter) publications, 7 i10-index publications and more than 300 citations. 